УДК 669.1.013.6-62

Б.Н. Вишневский,

T.O. Капустина,

Г.П. Войтковский,

А.А. Щербаков,

Ю.К. Абрамович,

А.С. Лебедев
Государственное предприятие

«Украинский институт по проектированию металлургических заводов», г. Днепр,

Украина

ООО «МЕТИНВЕСТ СЕЧСТАЛЬ»,

г. Запорожье, Украина

\title{
ПРОЕКТИРОВАНИЕ УСТАНОВКИ ГАЗГОЛЬДЕРОВ КОНВЕРТЕРНОГО ГАЗА НА МЕТАЛЛУРГИЧЕСКИХ ПРЕДПРИЯТИЯХ
}
B. Vyshnevskyi,
T. Kapustina,
H. Voitkovskyi,
O. Shcherbakov,
Y. Abramovych,
O. Lebediev

State-enterprise Ukrainian Institute For Designing Iron and Steel Works, Dnipro, Ukraine
LLC «METINVEST SICHSTEEL», Zaporozhye, Ukraine

\section{ENGINEERING OF CONVERTER GAS HOLDER UNITS FOR STEEL PLANTS}

Цель. Целью выполненных авторами проработок и расчетных исследований было предоставление проектировщикам данных и рекомендащий для обоснования применения газгольдеров конвертерного газа при его отводе «без дожигания окиси углерода». Это особенно важно при разработке так называемой «предпроектной документации» - основных технических решений, проектных предложений и технико-экономических обоснований, когда еще нет подписанного контракта $c$ Поставщиком оборудования конвертерного иеха, но Заказчик хочет оченить техническую возможность строительства и определить его предварительную стоимость, включая газгольдер.

Методика. Исходные данные и рекомендации для проектировщииков получены путем анализа имеющихся аналогов, проектных проработок и расчетных исследований на основе многолетнего опыта проектирования авторами конвертерных цехов, материалов фирм-изготовителей основных типов газгольдеров, а также патент Украины одного из авторов на усовершенствованный газгольдер. Рекомендации разработаны с учетом относящихся к проектированию Государственных стандартов, строительных норм, а также климатических условий Украины.

Результаты. Авторами разработаны следующие данные и рекомендащии для реального проектирования установки газгольдеров конвертерного газа, как специфических взрыво- и пожароопасных объектов сталеплавильного производства: уточненная методика приближенного определения вместимости газгольдера утилизируемого конвертерного газа, как топлива для нагревательных печей или паровых котлов заводской электростанции; конструкции и особенности основных типов газгольдеров большого объема низкого давления (до 4000 Па), включая усовершенствованный газгольдер согласно патенту Украины одного из авторов; схемы включения газгольдеров в газовую сеть предприятия; размещение газгольдеров на генплане предприятия с учетом предложенной авторами возможности их размещения на прудах-осветлителях; категория взрыво- пожароопасности установки газгольдера; сопоставление силь взрыва конвертерного газа и тринитротолуола; основные технико-экономические показатели строительства газгольдеров; воз- 
можная экономия природного газа за счет утилизаџии конвертерного газа для конкретного примера.

Научная новизна. Впервые разработана уточненная методика приближенного определения объема газгольдера конвертерного газа; определена сила взрыва конвертерного газа, хранящегося в газгольдере; усовершенствованный газгольдер с гофрированной оболочкой.

Практическая ценность. Использование приведенных данных, рекомендаций и разработок при реальном проектировании, особенно для «предпроектной документации». Материал может быть полезен также для студентов металлургических высших учебных заведений.

Ключевые слова: проектирование, конвертерный газ, газгольдер конвертерного газа, типь газгольдеров, размещение на генплане предприятия, экономия природного газа, техникоэкономические показатели.

DOI: $10.34185 / 0543-5749.2019-5-6-32-40$

Постановка проблемы. В настоящее время на большинстве металлургических предприятий Украины конвертерный газ (КГ) не используется, а сжигается на «свече» или дожигается в газоотводящем тракте.

Для его сбора, усреднения химического состава и теплоты сгорания с последующим использованием необходима установка газгольдера конвертерного газа (ГКГ).

Современные кислородные конвертеры снабжены регулируемыми системами отвода газа «без дожигания окиси углерода» с его охлаждением, очисткой, сбором в ГКГ, доохлаждением, доочисткой и выдачей потребителям. Актуальность данного вопроса объясняется ростом цен на природный газ и его дефицитностью. Утилизация КГ позволяет частично заменить природный газ в топливоиспользующих установках (нагревательные печи прокатных станов, паровые котлы и др.). Существуют варианты использования КГ при модернизации энергохозяйств заводов со строительством новых парогазовых электростанций (ПГЭС).

Цель. Обоснование применения ГКГ для возможности использования КГ в качестве топлива в технологических и энергетических установках металлургических предприятий Украины. Технико-экономические показатели установки ГКГ.

Изложение основного материала. В настоящей статье рассмотрены вопросы проектирования установки ГКГ, определение необходимого полезного объема газгольдера, схема включения его в газовую сеть, типы газгольдеров большого объема, ожидаемые техникоэкономические показатели.

Для проектирования газоотводящих трактов конвертеров технологами в качестве исходных данных выдаются: годовая производительность цеха, млн. т стали/год; количество конвертеров, шт.; емкость конвертера, т; интенсивность про- дувки плавки кислородом, м³/мин (при нормальных условиях); продолжительность плавки, мин, в т. ч. продолжительность продувки кислородом; количество плавок в сутки; годовое число часов работы цеха, ч/год; максимальный выход конвертерного газа из горловины конвертеpa, ${ }^{3} / 4$ (при нормальных условиях); его температура, ${ }^{\circ} \mathrm{C}$; график выхода конвертерного газа за время продувки; график работы конвертеров по времени с учетом возможной одновременности продувки двух конвертеров; состав газа по времени продувки, \% по объему.

Теплота сгорания КГ может составлять от

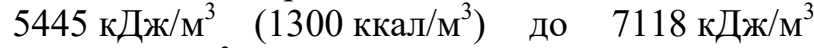
(1700 ккал/м ${ }^{3}$ ) при нормальных условиях (чем позже по времени продувки начинается утилизация КГ и чем раньше она заканчивается, тем выше теплота сгорания).

По этим данным при разработке предпроектной документации - основные технические решения, проектные предложения и проработки, стадия «технико-экономическое обоснование (ТЭО), когда еще, как правило, нет подписанного контракта с Поставщиком оборудования комплекса или цеха, предварительно выбирается состав газоотводящего тракта, включая ГКГ.

При этом рассматриваются: размещение на генплане, необходимые сносы и переносы существующих объектов и коммуникаций, объем геолого-топографических работ, варианты оборудования от разных Поставщиков и др. Прорабатываются также решения по автоматизированным системам управления технологическими процессами (АСУ ТП) и электроприводами и их связь с автоматизированной системой управления предприятием (АСУП), потребность в дополнительных к существующему положению штатах обслуживающего персонала, экономическая эффективность с учетом вариантности решений по снабжению энергоносителями, разрабатываются мероприятия по защите окружаю- 
щей природной среды, технике безопасности, промышленной санитарии и т. д.

С учетом предварительных данных по оборудованию, а также по имеющимся в распоряжении Проектировщика аналогичным работам, оценивается техническая возможность строительства и определяется его стоимость.

Следует отметить, что Инвесторы довольно часто и даже, как правило, заказывают разработку таких предпроектных материалов, чтобы предварительно, до выбора Поставщика и подписания контракта оценить стоимость и целесообразность строительства. Такая последовательность определяется современной реальной технологией проектирования строительства того или иного объекта.
Для стадий «проект» (европейский аналог «базисный инжиниринг»), который в Украине проходит экспертизу и утверждается, и «рабочая документация» («детальный инжиниринг»), по которой осуществляется строительство, Заказчик разрабатывает «Задание на проектирование» согласно ДБН А.2.2-3-2014, изм. 1 «Состав и содержание проектной документации на строительство». Заказчик передает указанное «Задание ...» Проектировщику одновременно с исходными данными по оборудованию от Поставщика для разработки этих стадий (согласно «Ведомости разделения поставок»).

Согласно [1], с. 20 выход КГ из горловины конвертера и его состав характеризуются данными, приведенными на рис. 1.

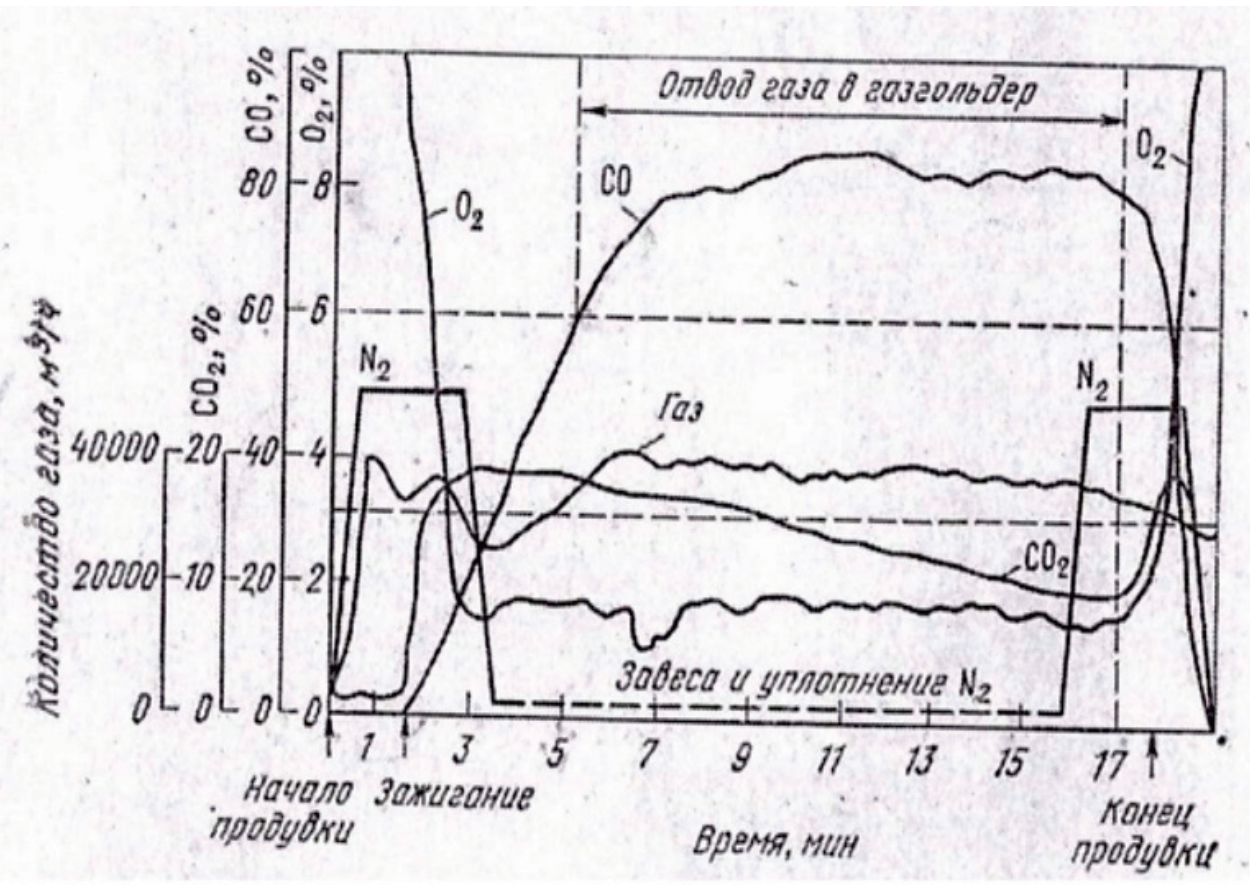

Рис. 1. График выхода конвертерных газов и их количество

На предпроектных стадиях вместимость ГКГ можно определять следующим образом.

В соответствии с [1] объем ГКГ определяется, исходя из $15000 \mathrm{~m}^{3}$ на 1 млн. т годовой выплавки стали. Например, для 2-х 180-тонных конвертеров при 3,46 млн. т жидкой стали/год полезная вместимость ГКГ составит: $15000 \times 3,46=51900 \mathrm{~m}^{3}$.

Авторами предлагается следующая уточненная методика приближенного определения полезной вместимости ГКГ. Количество утилизируемого газа определяется по формуле:

$$
\begin{aligned}
\mathrm{V}_{\mathrm{yг}}= & \mathrm{V}_{\text {гк }} \times \mathrm{K}_{\text {ву }} \times \mathrm{K}_{\text {сп }} \times \mathrm{K}_{\mathrm{cг}} \times \mathrm{K}_{\mathrm{ycp}} \times \\
& \times \mathrm{K}_{\mathrm{T}} \times \mathrm{K}_{\text {увл }} \times \mathrm{K}_{\text {д }} \times n, \mathrm{~m}^{3} / \mathrm{ч},
\end{aligned}
$$

где $\mathrm{V}_{\text {гк }}$ - выход газа из горловины конвертера, $\mathrm{M}^{3} /$ ч (при нормальных условиях);

$$
\mathrm{V}_{\text {гК }}=\mathrm{V}_{\mathrm{K}} \times \beta \times 60,
$$

где $\mathrm{V}_{\mathrm{K}}$ - интенсивность продувки кислородом, $\mathrm{m}^{3} /$ мин (при нормальных условиях); $\beta$ - коэффициент удельного выхода газа.

В настоящее время ведущие фирмыпоставщики оборудования принимают $\beta=1,82$.

Далее коэффициенты, учитывающие:

$\mathrm{K}_{\text {ву }}$ время утилизации без сброса газов на «свечу» в начале и в конце продувки:

$$
\mathrm{K}_{\mathrm{By}}=\frac{\tau_{\text {прод }}-\tau_{\text {св }}}{\tau_{\text {прод }}},
$$


где $\tau_{\text {прод }}, \tau_{\mathrm{cв}}-$ время продувки и сброса газа, мин; $\mathrm{K}_{\text {сп }}-$ совмещение продувок двух конвертеров. Можно принять $\mathrm{K}_{\text {сп }}=1,05 ; \mathrm{K}_{\text {сг }}-$ увеличение количества газов после их сгорания в нижней части охладителя конвертерных газов (ОКГ) при коэффициенте избытка воздуха $\alpha=0,1$. Согласно расчетам $\mathrm{K}_{\text {сг }}=1,17 ; \mathrm{K}_{\text {уср }}=\tau_{\text {прод }} / 60$ - часовое усреднение количества газов; $\mathrm{K}_{\mathrm{T}}$ - температуру газа перед ГКГ:

$$
\mathrm{K}_{\mathrm{T}}=\frac{72+273}{273}=1,26,
$$

где 72 - температура КГ на входе в ГКГ, ${ }^{\circ} \mathrm{C}$; $\mathrm{K}_{\text {увл }}-$ увеличение количества газа за счет его увлажнения в испарительном охладителе после ОКГ и в скруббере перед ГКГ.

Для заданных условий согласно расчетам $\mathrm{K}_{\text {увл }}=1,42$ (для климатических условий Украины); $\mathrm{K}_{\text {д }}-$ давление в ГКГ (2000 Па); $\mathrm{K}_{\text {д }}=1 / 1,02=0,98 ; \mathrm{n}-$ число продувок в час.

Для цеха в составе двух конвертеров по 180ст имеем: $\mathrm{V}_{\mathrm{K}}-600 \mathrm{Hм}^{3} / \mathrm{Mин;} \mathrm{число} \mathrm{плавок} \mathrm{в}$ сутки - 48 (2 продувки в час); продолжительность плавки - 45 мин., в т. ч. продувка 15 мин. Сброс газа на «свечу»- по 1 мин в начале и в конце продувки. Соответственно:

$$
\begin{gathered}
\mathrm{V}_{г к}=600 \times 1,82 \times 60=65520 \mathrm{Hм}^{3} / ; \\
\mathrm{K}_{\text {ву }}=(15-2) / 15=0,87 ; \quad \mathrm{K}_{\text {уср }}=15 / 60=0,25
\end{gathered}
$$

и часовое количество газа, подлежащее утилизации, будет:

$$
\begin{array}{rl}
\mathrm{V}_{\mathrm{yг}}=6 & 5520 \times 0,87 \times 1,05 \times 1,17 \times 0,25 \times 1,42 \times \\
\times 1,26 \times 0,98 \times 2=61394 \mathrm{~m}^{3} / \text { ч. }
\end{array}
$$

Это же количество КГ в течение часа должны равномерно использовать потребители.

Принимаем, что это часовое количество КГ равно полезному объему ГКГ при двух продувках в час по 15 мин. (время утилизации по 13 мин.) и интервале между продувками 45 мин.

Объем ГКГ зависит от этого интервала. Если увеличить его до 60 мин, то полезный объем ГКГ уменьшится в 1,33 раза, т. е. до $46161 \mathrm{~m}^{3}$ с одновременным соответствующим снижением среднечасового потребления. Таким образом, при более форсированном производстве стали нужен больший объем ГКГ с увеличением его потребления. Если объем ГКГ или потребление недостаточны, то будут сбросы газа на «свечу». При выборе ГКГ необходимо также учитывать максимально допустимую скорость подъема поршня ГКГ.
В каждом конкретном случае Поставщик по требованию Заказчика предоставляет техникоэкономический расчет-обоснование выбора ГКГ. При этом Заказчик сообщает желательный для него интервал между продувками, возможное минимальное и максимальное постоянное потребление КГ и другие необходимые данные для расчета. Все это может быть оговорено в контракте. При этом должны сопоставляться капитальные затраты на строительство ГКГ и экономия эксплуатационных затрат при использовании КГ в качестве топлива с определением срока окупаемости.

Следует подчеркнуть, что, как правило, Проектировщик не выбирает тип ГКГ, его конструкцию и не разрабатывает чертежи, это делает Поставщик. Проектировщик разрабатывает стадии «проект» и «рабочая документация» установки ГКГ согласно базисному и детальному инжинирингу Поставщика, который выбирается Заказчиком на тендерной основе.

Ниже приведены современные типы ГКГ большого объема низкого давления (до 4000 Па).

1. Дисковый ГКГ согласно [2] системы M.A.N. производства компании LEFFER (Германия) c гидравлическим уплотнением (см. рис. 2). В качестве уплотняющей жидкости применяется минеральное масло (холодостойкое и водоотталкивающее).

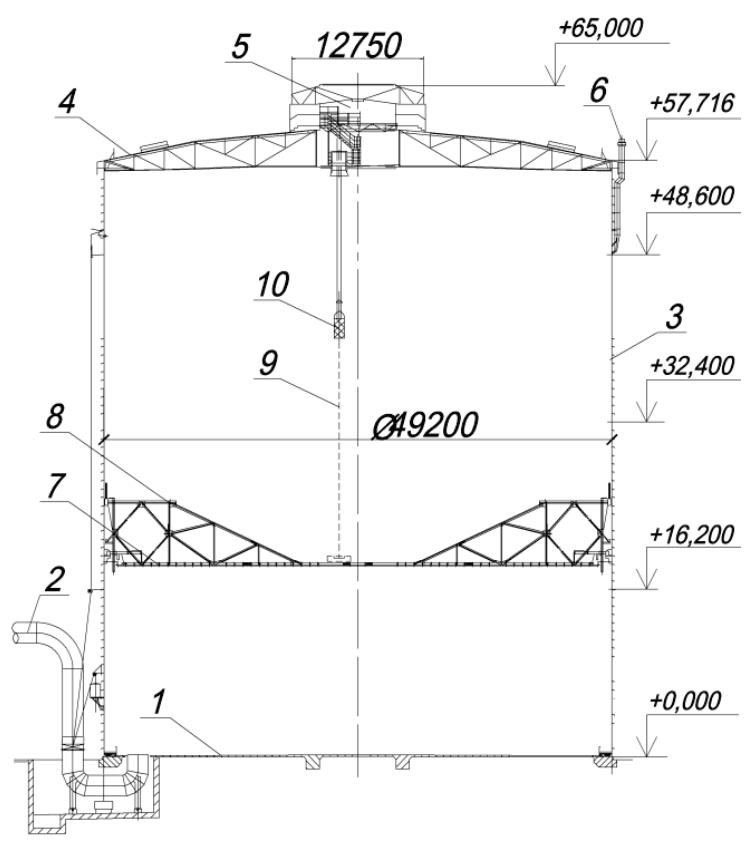

Pис. 2. Дисковый газгольдер системы "MAN", LEFER: 1- днище, 2- вход/выход газа (2 Ду 2000); 3- корпус; 4- крышка; 5- вытяжное устройство; 6- сбросные трубы и клапаны; 7- диск; 8- связующие конструкции диска; 9- управляющий трос внутреннего подъема; 10- устройство внутреннего подъема 
Основными преимуществами такого ГКГ являются: небольшая площадь основы диска, что имеет большое значение при стесненных условиях промышленной площадки; легкость хода диска, что позволяет поддерживать почти постоянное давление на всей длине его хода без значительных колебаний, максимально возможное давление на диск составляет 10 кПа; безопасный пуск и консервация установки; газонепроницаемое уплотнение между диском и корпусом обеспечивает безусловную надежность благодаря образованию масляного слоя; масло обеспечивает также антикоррозионную защиту поверхности стен газгольдера, находящихся в контакте с хранимым газом.

2. Сухой ГКГ Виггинса поршневого типа согласно [3,5], производства «Clayton Walker Gas holder» (Англия). В качестве уплотнения используется гибкая мембрана (см. рис. 3).

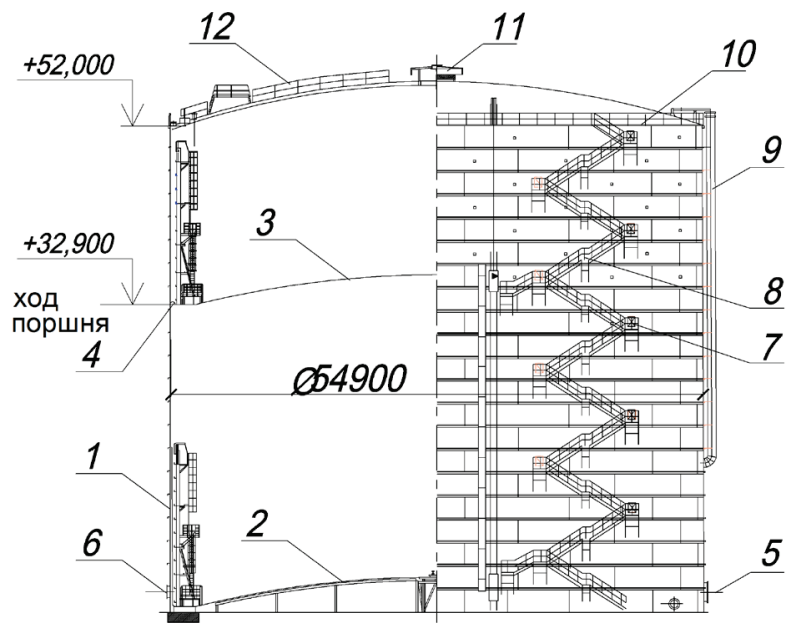

Рис. 3. Сухой газгольдер Виггинса: 1- резервуар; 2- опорная конструкция поршня; 3- поршень; 4- уплотнительная мембрана; 5- вход газа Ду 2000; 6- выход газа Ду 1500; 7- дверь в оболочке; 8- наружная лестница; 9- сбросные трубы и клапаны; 10 - площадка на кровле купола; 11 - центральное отверстие для выхода воздуха; 12- лестница к центральному отверстию

Этот ГКГ имеет следующие особенности: резервуар представляет собой цилиндрическую емкость, сваренную из углеродистой стали и состоит из кожуха, кровли и днища, толщина листов от 6 до 18 мм; поршень выполнен в виде стакана из углеродистой стали, герметизация пространства между внутренней поверхностью стенки кожуха резервуара и поршнем обеспечивается уплотняющей мембраной. Уплотняющая мембрана выполнена из специального, стойкого к воздействию газовой среды материала и слу- жит соединительным элементом между стенкой резервуара и поршнем, соединение мембраны с поршнем и стенкой резервуара выполнено герметично; для сохранения горизонтального положения поршня при движении предусматривается выравнивающее устройство в виде системы блоков, канатов и комплектов бетонных и стальных грузов (противовесов).

3. ГКГ с гофрированной оболочкой и системой регулирования давления газа, усовершенствованный согласно [4] - см. Рис. 4.

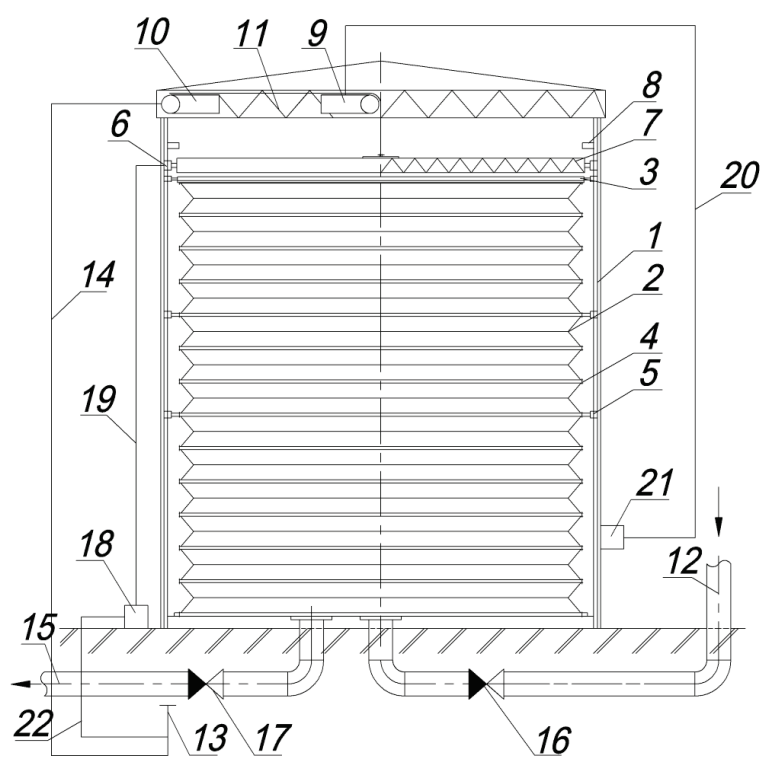

Рис. 4. Газгольдер с гофрированной оболочкой. Общий вид: 1 - каркас; 2- эластичная гофрированная оболочка; 3- верхняя шайба; 4- кольцо жесткости; 5- скользящие опоры; 6- скользящие опоры грузовой шайбы; 7- грузовая шайба; 8- ограничитель подъема грузовой шайбы; 9- механизм подъема; 10- тормозное устройство; 11- перекрытие; 12- подводящий газопровод; 13- датчик давления газа; 14- электролиния; 15- отводящий газопровод; 16- входной клапан; 17- выпускной клапан; 18- стабилизатор давления газа; 19- импульсная трубка; 20- электролиния; 21- нижний ограничитель; 22- импульсная линия.

По мере заполнения газом верхняя шайба газгольдера поднимается и растягивается эластичная гофрированная оболочка, при этом грузовая шайба находится в верхнем зафиксированном положении. При полностью заполненном газгольдере верхняя шайба входит в контакт с грузовой шайбой.

Подача газа потребителю под необходимым давлением обеспечивается за счет грузовой шайбы, которая выдавливает газ в заводскую сеть. Регулирование давления производится при 
помощи стабилизатора давления и датчика давления в соответствии с требованиями технологического процесса у потребителя. Режим работы газгольдера - периодический прием и постоянная равномерная выдача газа требуемого давления. Есть и другие типы газгольдеров.

ГКГ обязательно оборудуются молниеотводами.

Фундамент газгольдера представляет собой, как правило, единую фундаментную армированную плиту толщиной около 2 м.

По данным ГП «Укргипромез» имеется воз- можность утилизации конвертерного газа, в том числе со строительством ПГЭС на следующих предприятиях: ПАО «Днепровский металлургический комбинат», г. Каменское; ПАО «МК «Азовсталь», г. Мариуполь; ПАО «МК «Запорожсталь»; ПАО «АрселорМиттал Кривой Рог»; Алчевский металлургический комбинат (АМК); ЧАО «Енакиевский металлургический завод»;

При этом ПГЭС на АМК частично введена в эксплуатацию.

Возможный вариант схемы включения ГКГ в газовую сеть предприятия приведен на рис. 5.

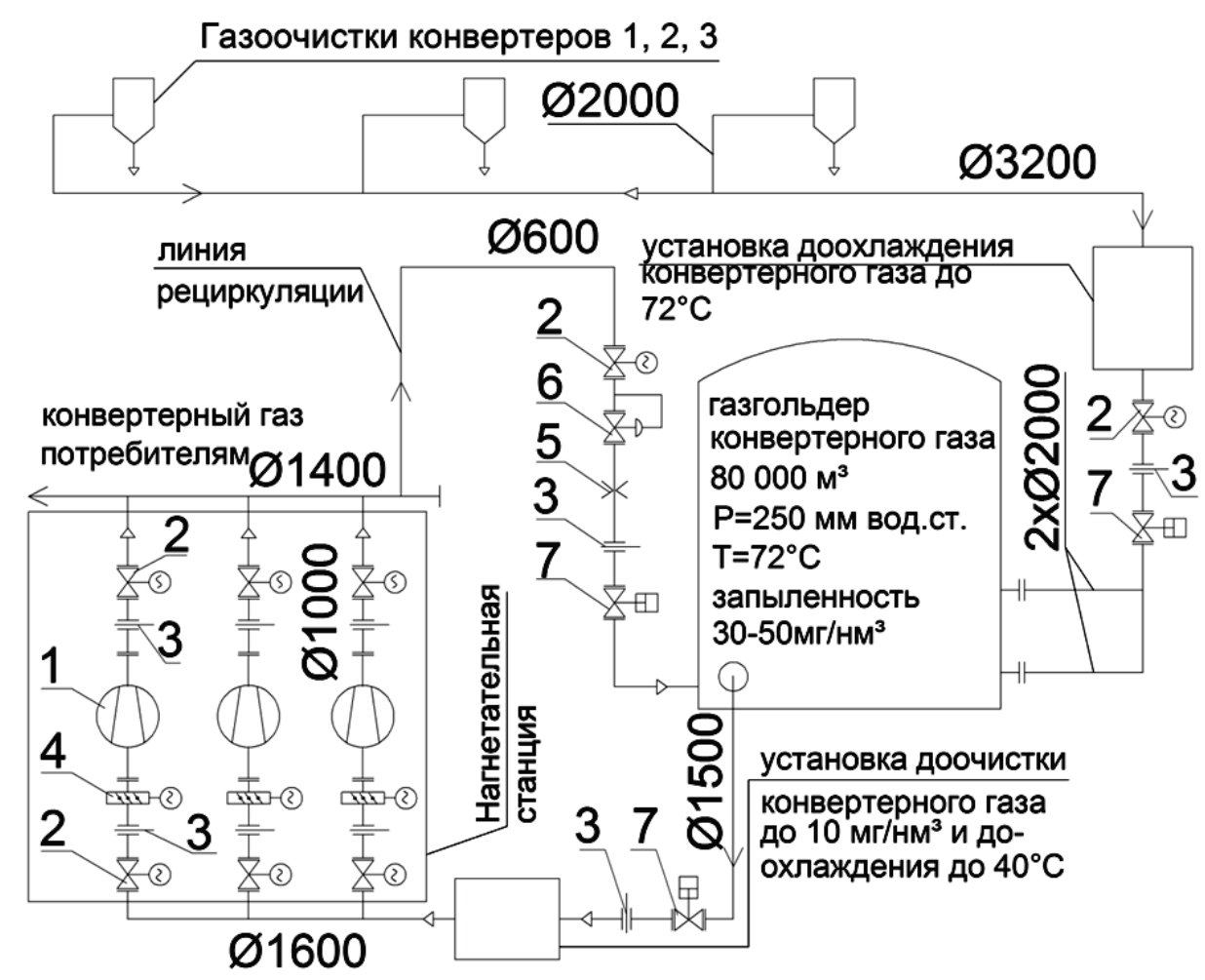

Рис. 5. Принципиальная схема подключения газгольдера: 1- газодувка; 2- электрифицированная задвижка; 3- листовая задвижка; 4- дроссель; 5- расходомерное устройство; 6- регулирующий клапан; 7- быстродействующий запорный клапан

Проектирование установки ГКГ регламентируется НПАОП 27.1-1.09-09 «Правила охраны труда в газовом хозяйстве предприятий черной металлургии» (ведомственные правила) и ДСТУ Б.В.1-36:2016 «Определение категорий помещений, зданий и наружных установок по взрывопожарной и пожарной опасности» (общегосударственные нормы).

Расположение на генеральном плане выполняется в соответствии со СНиПІІ-89-80 «Генплан и транспорт». По табл. 3 этого документа нормируется расстояние от ГКГ до зданий и сооружений: производственные и вспомогательные здания промышленных предприятий I и II степени огнестойкости $-30,0$ м; IV и $\mathrm{V}-36,0$ м.
Из-за больших разрывов до соседних зданий и сооружений размещение ГКГ часто затруднено и требует, как правило, сноса или переноса существующих объектов либо применения нестандартных решений.

Поэтому, например, при разработке в 2012г. ТЭО развития Енакиевского металлургического завода ГП «Укргипромез» было предложено размещение газгольдера на пруде-осветлителе.

В соответствии с п. 10 ДСТУ Б.В.1-36:2016 «Методы расчета значений критериев взрывопожарной и пожарной опасности наружных установок», таблица 6, выполнен «Расчет критериев взрывопожарной опасности газгольдера» для следующих условий: состав КГ, в \% по объему $\mathrm{CO}-70 \div 80 ; \mathrm{CO}_{2}-15 \div 20 ; \mathrm{O}_{2}-0,5 \div 0,8 ; \mathrm{N}_{2}-$ 
$3 \div 12$; содержание серы $-0,1 \div 0,2$ г/нм ${ }^{3}$; пределы взрываемости смеси конвертерного газа с воздухом: нижний $-15 \%$, верхний $-78 \%$; содержание пыли $5 \div 10 \mathrm{M \Gamma} / \mathrm{M}^{3}$, плотность КГ$\rho_{\Gamma}=1,35 \div 1,4$ кг $/ \mathrm{M}^{3}$ (при нормальных условиях); абсолютное давление газа в газгольдере при рабочих условиях $\mathrm{P}=0,1025 \mathrm{MПа;} \mathrm{объем} \mathrm{газа} \mathrm{-}$ $\mathrm{V}=80000 \mathrm{~m}^{3}$; температура газа в ГКГ Т $=353 \mathrm{~K}$; диаметр ГКГ - 50 м, высота - 60 м. Поскольку КГ, в основном, состоит из окиси углерода $(\mathrm{CO}-70 \div 80 \%)$, то согласно ГОСТ 12.1.011-78, Приложение 3 «Распределение взрывоопасных смесей по категориям и группам» КГ относится к категории взрывоопасности и группе взрывоопасности - IIA-T1. Результаты расчета:

- горизонтальный размер зоны, который ограничивает область концентраций, превышающих нижний концентрационный предел распространения пламени $-R_{\text {нкпр }}=241$ м;

- избыточное расчетное давление в случае воспламенения газовоздушной смеси в ГКГ на расстоянии $30 \mathrm{м}-\Delta P=162,18$ кПа.

Сравнение полученных критериев взрывопожарной опасности с критериями для установок категории «Ан» согласно таблице 6 указанного ДСТУ: $R_{\text {нкпр }}=241 \mathrm{~m}>30 \mathrm{~m}$;

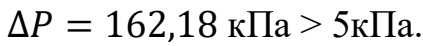

Таким образом, ГКГ объемом $80000 \mathrm{~m}^{3}$ относится в Украине к высшей категории по взрывопожарной опасности - «Ан» (для наружных установок).

Кроме того, для относительной оценки взрывоопасности установки ГКГ был выполнен расчет тротилового эквивалента взрыва КГ по методике, изложенной в Приложении 3 «Общих правил взрывобезопасности для взрывоопасных химических и нефтеперерабатывающих производств» (М.: Металлургия, 1988).

Расчет показал, что тротиловый эквивалент взрыва КГ, находящегося в ГКГ вместимостью
$80000 \mathrm{~m}^{3}$, очень большой и равноценен взрыву 8900 кг тринитротолуола (ТНТ). ТНТ, тол, тротил обозначают одно и то же вещество.

В составе пояснительной записки к проекту установки ГКГ разрабатываются в обязательном порядке все разделы согласно ДБН А.2.2-3-2014, изм. 1.

Материалы раздела «Оценка влияния на окружающую среду (ОВОС)» рассматривают основные аспекты влияния на нее установки ГКГ. При разработке данного раздела необходимо учитывать, что по токсичности конвертерный газ относится к сильнодействующим ядовитым веществам (СДЯВ) из-за наличия окиси углерода $(\mathrm{CO})$ в количестве $70-80 \%$ (по объему). Большое значение имеет расположение ГКГ относительно существующих цехов предприятия и селитебных территорий.

Из-за существенного увеличения объема хранимого горючего газа в ГКГ, по сравнению с существующим положением на предприятии, согласно разделу «Идентификация объекта повышенной опасности» предполагается возможная корректировка действующей на предприятии «Декларации безопасности объекта (объектов) повышенной опасности».

Согласно изложенному видно, что ГКГ обеспечивает возможность утилизации конвертерного газа как топлива. Например, согласно [6] для условий строительства современного комплекса в составе 3-х конвертеров по 300 т, МНЛЗ и двух прокатных станов производительностью по 2,5 млн т горячекатаных рулонов/год и ГКГ за счет замены природного газа при его цене $250 \$ / 1000 \mathrm{~m}^{3}$ (при нормальных условиях) конвертерным газом в нагревательных печах экономия составит около 7,7 млн. \$/год.

В таблице 1 приведены основные техникоэкономические показатели строительства газгольдеров.

Таблица 1. Технико-экономические показатели строительства газгольдеров

\begin{tabular}{|l|c|c|}
\hline Наименование & газгольдер системы М.А.N. & сухой газгольдер Виггинса \\
\hline Номинальная вместимость, ${ }^{3}$ & 90000 & 80000 \\
\hline Полезная вместимость, ${ }^{3}$ & 80000 & 71000 \\
\hline Максимальное расчетное давление, кПа & 300 & 300 \\
\hline Рабочее давление, кПа & 250 & 250 \\
\hline Максимальный диаметр резервуара, м & 49,2 & 55,7 \\
\hline Максимальная высота подъема диска, $\mathrm{M}$ & 47,8 & 32,90 \\
\hline Высота газгольдера до края крыши, м & 58,716 & 52,0 \\
\hline Общий вес газгольдера, т & 1295 & 1470 \\
\hline Ориентировочная стоимость, тыс. евро* & 15187,5 & 11653,0 \\
\hline
\end{tabular}

*- стоимость ГКГ необходимо каждый раз запрашивать у Поставщиков 
Выводы. В статье рассмотрены вопросы и аспекты современной технологии проектирования установки ГКГ.

1. ГКГ обеспечивает возможность утилизации КГ, как топлива, для технологических и энергетических агрегатов. В настоящее время практически на всех комбинатах полного металлургического цикла Украины актуальна их установка. Она сдерживается только возможностью инвестиций в крупные проекты по модернизации черной металлургии в реальных экономических условиях.

2. При строительстве современного комплекса (3 конвертера по 300 т +МНЛ3+2 прокатных стана производительностью по 2,5 млн т/год горячекатаных рулонов за счет замены природного газа (при его цене $250 \$ / 1000 \mathrm{~m}^{3}$ ) конвертерным газом экономия может составить около 7,7 млн.\$/год.

3. При затруднениях с размещением ГКГ на генплане предприятия можно рекомендовать их расположение на прудах-осветлителях или отстойниках.

\section{Библиографический список}

1. Бережинский А.И., Циммерман А.Ф. Охлаждение и очистка газов кислородных конвертеров. Москва : Металлургия, 1983, 263 с.

2. Каталог «Дисковый газгольдер» Леффер (ВАДО Интернешнл СНГ). URL: http://www. vado.ru/.

3. Строительство сухого газгольдера Виггинса с одинарным уплотнением. ООО «Проектно-строительное предприятие «Азовинтекс»; ООО «Внешнеэкономическое предприятие «Азовимпекс». URL: http:// azovintex.com/.

4. Газгольдер: патент на корисну модель 31193 Україна: МПК (2006) F17 В 1/00. № 200714414; заявл. 20.12.2007; опубл. 25.03.2008. Бюл. № 6.3 c.

5. Проекты в области металлургии. Газгольдеры для хранения вторичных металлургических газов Алчевского металлургического комбината. Институт проблем экологии и энергосбережения 2004-2015. URL: http://www.ipee. org.ua/.

6. Проектирование газосмесительных станций металлургических предприятий / Вишневский Б.Н. и др. Металлургическая и горнорудная промышленность. 2017. № 2.

\section{References}

1. Berezhinskii, A. I., \& Tsimmerman, A. F. (1983). Okhlazhdenie i ochistka gazov kislorodnykh konverterov. Moskva : Metallurgiia.
2. Katalog "Diskovyi gazgoldeR" Leffer (VA$D O$ Interneshnl SNG). Retrieved from http://www.vado.ru/.

3. Stroitelstvo sukhogo gazgoldera Vigginsa s odinarnym uplotneniem. OOO «Proektnostroitelnoe predpriiatie «AzovintekS»; OOO «Vneshneehkonomicheskoe predpriiatie «AzovimpekS». Retrieved from http:// azovintex.com.

4. Abramovich, Iu. K., Krivchenko, Iu. S., Bychkov, S. V., Vovk, V. M., \& Solovev, V. M. (2008). Ukraine. Patent No. 31193.

5. Proekty v oblasti metallurgii. Gazgoldery dlia khraneniia vtorichnykh metallurgicheskikh gazov Alchevskogo metallurgicheskogo kombinata. Institut problem ehkologii i ehnergosberezheniia 2004-2015. Retrieved from http://www.ipee.org.ua/.

6. Vishnevskii, B. N. et al. (2017). Proektirovanie gazosmesitelnykh stantsii metallurgicheskikh predpriiatii. Metallurgicheskaia $i$ gornorudnaia promyshlennost, (2).

Мета. Метою виконаних авторами розробок та розрахункових досліджень було забезпечення проектувальників даними і рекомендачіями для обтрунтування застосування газгольдерів конвертерного газу при його відводі «без спалювання окислу вуглецю». Це особливо актуально при розробках так званої «передпроектної документації»- основних технічних рішень, проектних пропозииій та техніко-економічних обтрунтувань, коли ще немає підписаного контракту з Постачальником обладнання конвертерного цеху, але Замовник хоче оцінити технічну можсливість будівництва і попередньо визначити його вартість, включаючи газгольдер.

Методика. Вихідні дані та рекомендаиії для проектувальників отримані шляхом аналізу наявних аналогів, проектних розробок і розрахункових досліджень на основі багаторічного досвіду проектування авторами конвертерних иехів, матеріалів фірм-виготовників основних типів газгольдерів, а також патент України одного з авторів на вдосконалений газгольдер. Рекомендації розроблені з врахуванням Державних стандартів, будівельних норм, щчо відносяться до проектування, а також кліматичних умов України.

Результати. Авторами розроблені наступні дані та рекомендаиії для реального проектування встановлення газгольдерів конвертерного газу, як спечифічних вибухо- та пожежонебезпечних об'єктів сталеплавильного виробництва: уточнена методика приблизного визначення місткості газгольдера конвертерного газу, що утилізується як паливо для нагрівальних печей 
та парових котлів електростаниії заводу; конструкиї та особливості основних типів газгольдерів великого об'єму малого тиску (до 4000 Па), включаючи вдосконалений газгольдер згідно з патентом Украӥни одного з авторів; схеми включення газгольдерів в газову мережу підприємства; розміщення газгольдерів на генплані підприсмства з врахуванням запропонованої авторами можливості їх розмішення на ставках-освітлювачах; категорія вибухо- пожежонебезпеки встановлення газгольдера; сnівставлення сили вибуху конвертерного газу та тринітротолуолу; техніко-економічні показники будівниитва газгольдерів; можлива економія природного газу завдяки утилізаџї конвертерного газу для конкретного прикладу.

Наукова новизна. Вперше розроблена уточнена методика приблизного визначення об'єму газгольдера конвертерного газу; визначена сила вибуху конвертерного газу, щзо зберігається в газгольдері; вдосконалений газгольдер з гофрованою оболонкою.

Практична цінність. Використання наведених даних, рекомендацій та розробок при реальному проектуванні, особливо для «передпроектної документації». Матеріал може бути корисним також для студентів вищчих навчальних закладів.

Ключові слова: проектування, конвертерний газ, газгольдер конвертерного газу, типи газгольдерів, розмімення на генплані підприємства, економія природного газу, технікоекономічні показники.

Purpose. The purpose of the studies and calculation analyses carried out by the authors was to provide designers with data and recommendations for justification of the use of gas holders when converter gas is disposed "without carbon monoxide post-combustion". This is especially important when developing the so-called "pre-project documentation" - main technical solutions, design proposals and feasibility studies, when there is no signed contract with the converter equipment supplier, but the client wants to evaluate the technical feasibility of construction and determine its preliminary cost, including gas holder unit.

Methods. Initial data and recommendations for designers have been obtained by analyzing existing analogues, design studies and calculation analyses based on many years of experience in engineering converter shops, documentation of manufacturers of the main types of gas holders, as well as a patent of Ukraine by one of the authors for an improved gas holder. The recommendations have been developed with due consideration of the State standards related to the engineering, building codes, as well as the climatic conditions of Ukraine.

Results. The authors developed the following data and recommendations for the real engineering of converter gas holders, being specific explosive and fire hazardous objects of steelmaking: an improved methodology for approximate determination of the gas holder capacity for recoverable converter gas as fuel for heating furnaces or steam boilers of a captive power plant; designs and specific features of the main types of low-pressure large-volume gas holders (up to $4000 \mathrm{~Pa}$ ), including an improved gas holder according to the patent of Ukraine by one of the authors; schemes for connecting gas holders to the gas network of an enterprise; siting of gas holders in general layout of the enterprise, taking into account possibility of placement of the same on clarifying ponds as proposed by the authors; category of explosion and fire hazard of a gas holder; comparison of explosion force of the converter gas and trinitrotoluene; main technical and economic indicators of the gas holder installation; possible saving of natural gas due to recovery of converter gas for a specific example.

Originality. For the first time an improved methodology has been developed for the approximate determination of the volume of a converter gas holder; the explosion force of the converter gas stored in the gas holder has been determined; an improved gas holder with corrugated shell.

Practical implications. Use of the defined data, recommendations and developments during real engineering, especially for "pre-project documentation". The information may also be useful for students of metallurgical higher educational institutions.

Key words: engineering, converter gas, converter gas holder, kinds of the gas holders, siting in general layout of an enterprise, natural gas saving, technical-and-economic indices.

Рукопис надійшов 22.10.2020 